\title{
Functional MRI of the Lung
}

\author{
Y. Berthezène*
}

Hôpital de la Croix Rousse, Service de Radiologie, Laboratoire Creatis-LRMN CNRS - UMR 5220- U 630 Inserm, 103, Grande rue de la Croix Rousse, 69317 Lyon Cedex 04, France

\begin{abstract}
Imaging of the pulmonary parenchyma represents a unique challenge for MRI. Limited signal is caused by low proton density, susceptibility artefacts, and physiological motion (cardiac pulsation, respiration). Improvements in MRI techniques have extended the potential for investigations of pulmonary parenchymal disease with the evaluation of lung perfusion. More recently inhalation of non proton-MRI nuclei such as hyperpolarized gases (3He or 129Xe) can provide functional ventilation images.
\end{abstract}

Keywords: Lung diseases, pulmonary function, lung MRI, lung ventilation, lung perfusion.

\section{INTRODUCTION}

While proton-MRI has emerged in the past few years as a technique of choice for imaging many organs and diseases, lung parenchyma still remains one of the most difficult tissues to be imaged because of three main factors:

- The low density of air-filled lung parenchyma, resulting in low proton density and weak NMR signal intensity

- $\quad$ The important motion artefacts due to physiological displacements (cardiac and respiratory motions);

- $\quad$ Susceptibility effects induced by multiple air and tissue interfaces which cause many local gradients responsible for very low values of $\mathrm{T} 2$.

Several strategies have been developed to overcome these difficulties. Image acquisition during breathhold or using respiratory gating and/or EKG triggering procedures results in reduced motion artefacts and a fixed position of the diaphragm and the cardiac cavities during image reconstruction. Susceptibility artefacts can be minimized by the use of spin echo sequences and very short echo-time. Nonetheless, the weak NMR signal remains the major drawback for lung MRI. In this context, the development of new contrast agents is of crucial importance for increasing the NMR signal from the lung. Extra cellular or strictly intravascular contrast agents administered intravenously (Gd chelates) have been used to enhance lung parenchyma and evaluate lung perfusion. Beside proton MRI, other nuclei can be used for MRI. They include Helium-3, Xenon-129 and Fluorine-19. ${ }^{3} \mathrm{He}$ and ${ }^{129} \mathrm{Xe}$ are inert gases, and they can be applied easily by inhalation.

\section{PROTON IMAGING}

Low spin density is the major drawback for MRI of the lung, especially for the visualization of normal lung

*Address correspondence to this author at the Hôpital de la Croix Rousse, Service de Radiologie, Laboratoire Creatis-LRMN CNRS - UMR 5220- U 630 Inserm, 103, Grande rue de la Croix Rousse, 69317 Lyon Cedex 04, France; Tel: 334720718 80; Fax: 334720718 86;

E-mail: yves.berthezene@creatis.univ-lyon1.fr parenchyma and of lung diseases with loss of tissue such as emphysema. It can be approached by the use of gradientecho sequences with short repetition times, low flip angle, a higher number of acquisitions and large voxels. In many lung diseases, the amount of tissue, fluid and/or cells is increased by the pathological process. Thus, a higher number of protons are accessible, and significant improvements of the SNR can be achieved. To make use of the higher spin density short echo times are important to avoid signal loss from T2 relaxation [1]. However, in various cases such a disease related increase of spin density is not sufficient for accurate delineation, characterization and diagnosis of the disease process. Paramagnetic contrast agents have the potential to increase the MR signal from the lungs when using very short echo times which reduce susceptibility effects arising from air-tissue interfaces. They are used for enhancement of nodules or consolidations, for MR angiography or for perfusion imaging.

\section{Chronic Infiltrative Lung Disease}

In Chronic infiltrative lung disease, the pathology itself induces an increase in proton density and a reduction of susceptibility artefacts [2]. Alveolitis demonstrates high signal intensity on $\mathrm{T} 1 \mathrm{w}$ and $\mathrm{T} 2 \mathrm{w}$ images and also shows manifest enhancement after contrast administration. Signal intensity correlated with clinical severity of disease and potential response to therapy. Successful anti-inflammatory treatment decreasing the activity of alveolitis or development of fibrosis in the natural course of the disease are associated with a decrease in signal intensity. King et al. have shown that, the administration of a contrast agent significantly improved the detection of honeycombing but not the detection of ground-glass opacities [3]. Although, extent and distribution of airspace disease is clearly depicted at MRI, it is still inferior to $\mathrm{CT}$ regarding anatomic assessment and demonstration of fibrosis, i.e. parenchymal bands and reticular abnormalities [5]. In animals, macromolecular contrast agents may improve the differentiation between alveolitis and fibrosis even further [6]. In the active alveolitic phase, leakage of macromolecules from the intravascular into the extravascular compartment was observed. In the fibrotic phase, enhancement was markedly diminished which 
indicates a decrease in plasma volume within the fibrotic lung [6]. Macromolecular contrast agents will greatly improve the assessment of the inflammatory alveolitic processes in the future.

\section{Pulmonary Edema}

Magnetic resonance imaging has also been used successfully to evaluate the lung water content qualitatively and quantitatively [7]. These properties can be used to characterize the microvascular barrier function within the lung. In hydrostatic pulmonary edema in rats, the $\mathrm{T} 1$ relaxation time was significantly longer than in normal controls, whereas T2 relaxation time was not different. In permeability pulmonary edema, however, $\mathrm{T} 1$ and $\mathrm{T} 2$ relaxation times were significantly longer than in normal controls [8]. It could also be demonstrated that $\mathrm{T} 1$ and $\mathrm{T} 2$ are linearly related to extravascular lung water in an induced permeability edema in rats [9]. In normal excised pig lungs, a $95 \%$ correlation between MR measurements and gravimetric lung water content was found [10]. Using a three-dimensional gradient- echo sequence which is sensitive to water the entire lung can be covered with a spatial and temporal resolution sufficient to observe the development of pulmonary edema in an experimentally induced acute respiratory distress syndrome [11]. The results indicate that edema formation can be imaged regionally and quantified globally estimating the mismatch of transcapillary filtration flow and lymph clearance [12].

Lung water sequences were also successfully applied in humans. Measurements of average lung density were easily performed. Lung intensity decreased with full inspiration. It gives an estimate of regional lung expansion. Regional measurements of lung density are used to determine lung density gradients. These gradients did not show a significant change in the prone or the supine position. From the calculated lung density gradients, pleural pressure gradients can be calculated. They also decrease with full inspiration. In normal volunteers, MR measurements of these parameters were similar to those obtained with more invasive procedures [10]. Edema and infiltrative lung disease increase lung density and decrease the elastic properties of the lung, and MR measurements of lung water content may prove useful in the assessment of parenchymal lung disease. In animal models, using macromolecular contrast media, pulmonary edema of different etiologies (increased vascular pressure $v s$ damaged capillary barriers) can be separated [13]. Measurements of the total intravascular volume using macromolecular contrast agents and the determination of total lung water using a multi-spin-echo sequence allow for an accurate calculation of extravascular lung water. There was a high correlation with gravimetric reference measurements in the quantitation of pulmonary edema.

Although some approaches are ready to use, MRI of pulmonary edema has not been established in clinical routine.

\section{Perfusion}

There are several different approaches to image lung perfusion. Some of them are based on spin tagging techniques, called Flow sensitive Alternating Inversion Recovery (FAIR) and FAIR with an extra radiofrequency pulse (FAIRER). The blood water is magnetically labeled and used as an endogenous, freely diffusible tracer. With inversion times of 1000-1500 ms enhancement of the lung parenchyma and the peripheral pulmonary vessels down to the subsegmental level was observed [14]. The classical method requires the administration of intravenous contrast agent (Gd-chelates) to evaluate lung perfusion. Gd-chelates will reduce the longitudinal relaxation (T1) of blood resulting in an increase in signal intensity. Usually, imaging is performed during the first pass of the contrast agent through the lung using a fast imaging sequence with a short TE to reduce susceptibility artefacts.

Changes of signal intensity during the first passage are detected with inversion recovery 2D turbo-FLASH with ultrashort TE or 3D FISP with short TR and short TE [15, 16]. For both techniques, the non-enhanced images are subtracted from the enhanced images, such as in digital subtraction angiography. The final image is a selective perfusion map of the lung. For the $2 \mathrm{D}$ sequence timeintensity curves were calculated to assess the time course of perfusion [17]. From the 3D FISP acquisition maximum intensity projection of perfusion were generated and assessed visually [18]. These techniques were successfully used to detect perfusion defects in patients with pulmonary embolism [19] (Fig. 1a). In a prospective comparative study with perfusion lung scintigraphy, perfusion MRI had an average sensitivity of $69 \%$ and specificity of $91 \%$ for the detection of perfusion defects. The overall agreement between MR and scintigraphy appeared to be good (kappa_0.63) [20]. MR perfusion imaging was also capable to demonstrate physiological preferences of pulmonary perfusion. The gravity-dependence of lung perfusion was observed in volunteers who were investigated in supine and prone position [21]. In patients after single lung transplantation, preferred perfusion of the dorsal parts of the lung in supine position was clearly demonstrated by a higher increase in signal intensity [22]. These preliminary data in patients suggest that perfusion imaging might be quite helpful in the diagnosis of pulmonary embolism. It remains unclear whether perfusion imaging will provide clinically helpful information on perfusion defects and heterogeneity in emphysema or chronic infiltrative lung disease.

\section{Oxygen-Enhanced Lung MRI}

The use of $100 \%$ oxygen as a paramagnetic contrast agent in MR imaging of the lung was first proposed by Edelman, Chen and Stock [23-25]. A shortening of the T1 of the lung parenchyma on the order of $100-200 \mathrm{~ms}(10 \%)$ was reported during breathing $100 \%$ oxygen, resulting in a signal intensity variation on the order of $20 \%$ on optimized T1weighted sequences (Fig. 1b). The optimum dosage for $100 \% \mathrm{O}_{2}$ was shown to be $15 \mathrm{~L} / \mathrm{min}$ [26]. Administration of $100 \%$ oxygen with this dosage has been shown to produce oxygen concentrations in the lung of $60-80 \%$ [27]. Above 15 $\mathrm{L} / \mathrm{min}$, a plateau in signal intensity increase was observed. Several investigators have suggested that prolonged hyperoxia due to $100 \%$ oxygen inhalation can cause diffuse alveolar damage and lung fibrosis [27]. Such noxious effects were observed on animal experiments and occurred during prolonged hyperoxia of several hours or days, whereas in $\mathrm{O}_{2-}$ enhanced MRI lung studies, hyperoxia lasts less than $1 \mathrm{~h}$ in total and is alternated with periods of normoxia. MR images 
are acquired with the subjects in a supine position alternately inhaling room air and $100 \%$ oxygen using a non-rebreathing ventilation mask or a mouthpiece associated with a nose clamp. A typical $\mathrm{O}_{2}$ inhalation paradigm consists of subjects alternately breathing room air for about $1 \mathrm{~min}$ and $100 \%$ oxygen for about $2 \mathrm{~min}$. The difference between the images of the two states yields the oxygen-enhanced ventilation images. Ventilation maps can be expressed as the percentage of relative enhancement. Image acquisition can be triggered either right after the air/ $\mathrm{O}_{2}$ switch for assessment of wash-in or washout or about $120 \mathrm{~s}$ after the switch to allow static imaging.

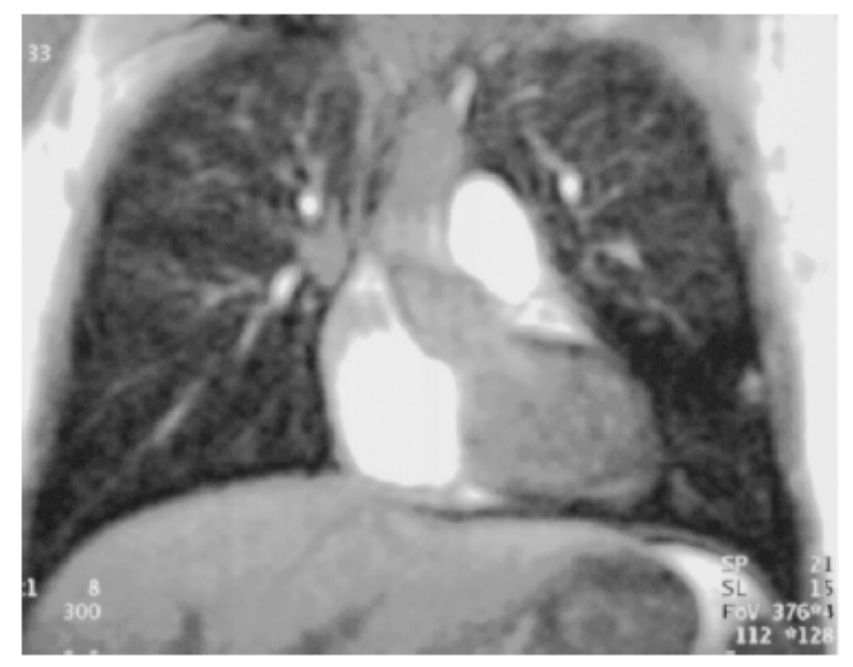

a

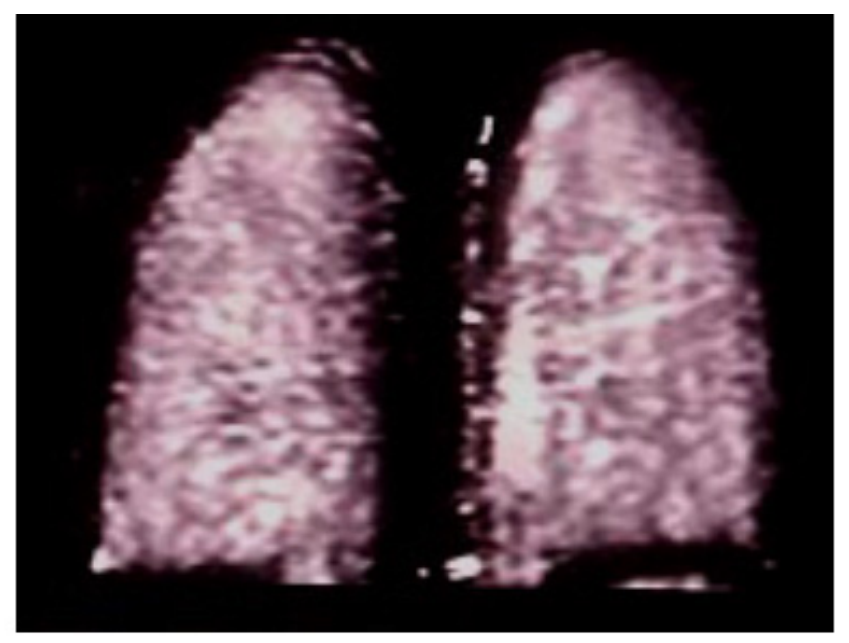

$\mathrm{b}$

Fig. (1). Patient with a suspected pulmonary embolism. Gadolinium perfusion image demonstrates a perfusion defect in the left lower lobe (a). Oxygen coronal ventilation image demonstrates a homogeneous lung enhancement (b).

Simultaneous cardiac and respiratory synchronization has been shown to improve image quality [28] with a reduced variability of signal intensity and diaphragm mismatch. Image acquisition can be performed during quiet breathing, at the end of expiration when the signal intensity is higher (due to higher proton density and smaller susceptibility effects) as compared with acquisition at full inspiration. Only short suspensions of breathing of less than $3 \mathrm{~s}$ are required during acquisition, which is especially important for patients who could have difficulties in holding their breath at end-expiration.

Several studies aimed to compare signal intensity changes or signal intensity time course with DLCO, standard pulmonary function tests, HRCT or scintigraphy in healthy volunteers and patients with pathologic diffusive capacity such as idiopathic lung fibrosis or emphysema [27, 29]. In patients, mean enhancement ratio was significantly lower and signal intensity time course showed a delayed signal intensity increase [27, 29]. Weak and heterogeneous enhancement of $10-26 \%$ was found in patients with pulmonary emphysema [27]. Regional differences that correlated with findings on radiographs and CT scans were seen on the signal intensity slope and on the maps of signal intensity change. Enhancement was excellently correlated with DLCO [27] and strongly correlated with HRCT emphysema score. Mean upslope of enhancement calculated from dynamic acquisitions was strongly correlated with forced expiratory volume in $1 \mathrm{~s}$ (FEV1) and had a good to excellent correlation with DLCO [29]. A prospective study in 30 patients with lung cancer, showed that post-surgical FEV1 and predicted oxygen enhanced MRI FEV1 was excellently correlated [27].

\section{HYPERPOLARIZED GASES}

Compared with conventional water proton imaging, MRI of gases is inherently limited by the much lower spin density of the gas phase (typically three orders of magnitude drop in spin density).

One effective way to circumvent the low NMR sensitivity of gases is to acquire MR signal from the socalled hyperpolarized (HP) or laser-polarized gases.

Among other parameters, the NMR signal-to-noise ratio (SNR) per unit volume is depending linearly on the polarization level $\mathrm{P}$, defined as the percentage of the maximum achievable nuclear macroscopic magnetization of the sample. For the nuclei of the atoms of interest in biomedical NMR (hydrogen, fluorine, phosphorus, sodium, etc), the value of the polarization level at thermal equilibrium, the so-called Boltzmann polarization level, is in the order of a few parts per million ( $\mathrm{ppm})$. However, nuclear polarization high above thermal equilibrium can be achieved by the use of appropriate polarization techniques.. The polarization levels can be typically increased by 5 orders of magnitude compared with the Boltzmann equilibrium level, resulting in a similar increase in detectable NMR signal.

\section{MR Imaging Using HP 3He and 129Xe}

The large NMR signal offered by HP gases allows one to image their distribution in the pulmonary tree and the alveolar spaces. The first NMR biomedical application of HP 129Xe was reported in 1994 with intrapulmonary space imaging of excised mouse lungs [31]. The first in vivo animal lung ventilation images obtained using HP $3 \mathrm{He}$ were reported one year later [32] followed by the first human lung images $[33,34]$. Imaging of the intrapulmonary distribution of HP gases can be used for the visualization of ventilated airspaces. The spatial resolution of lung ventilation images obtained using $3 \mathrm{He}$ exceed by an order of magnitude the spatial resolution that are routinely obtained with 
scintigraphy techniques using radioactive gases. In human studies, typical spatial resolution in the millimeter range are reported (Fig. 2), while in rodents studies sub-millimetric resolution (Fig. 3) is usually reached [36]. Spatial resolution obtained with $129 \mathrm{Xe}$ ventilation images is typically 3 to 5 times lower due to reduced available SNR. Physical and chemical interactions of the HP gases with their biological environment can be advantageously exploited for obtaining structural or functional information on the lungs. The most commonly used physical parameters are the diffusion length, the longitudinal relaxation times, the velocity, the flow and the chemical shift of the HP gases.

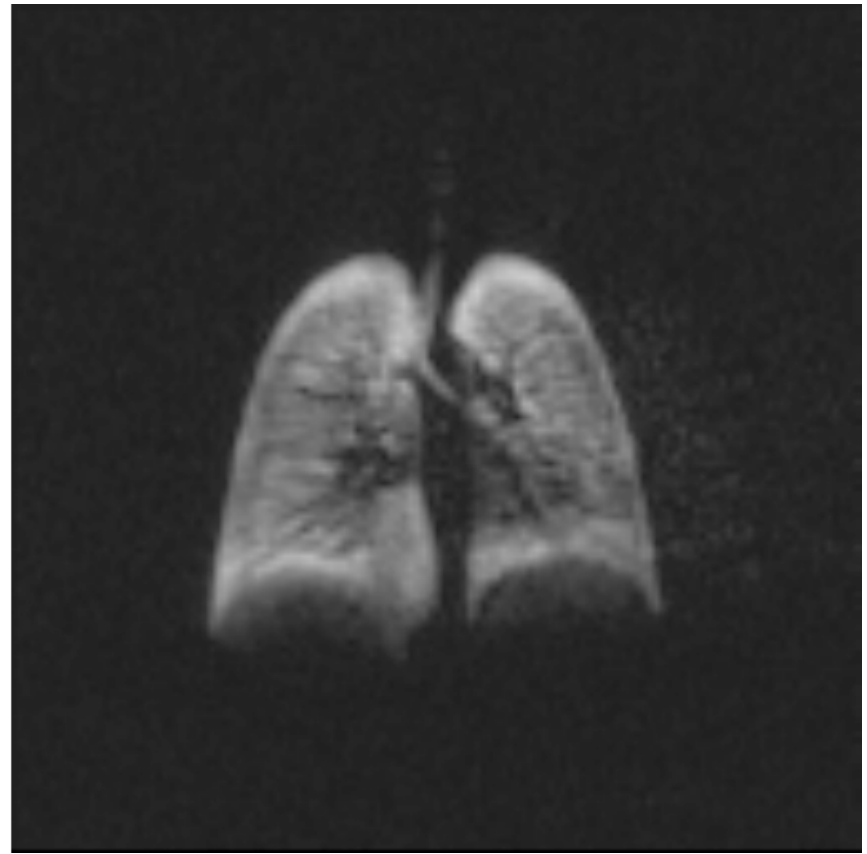

Fig. (2). Coronal hyperpolarized $3 \mathrm{He}$ gas $\mathrm{MR}$ image in a normal volunteer.

MR diffusion imaging is a well known technique applied essentially for measuring the so-called apparent diffusion coefficient (ADC) of water in tissues. The ADC values of $\mathrm{HP}$ gases in airspaces depend on gas composition (dilution of HP gases in pulmonary gases) and above all on the restriction of gas atoms diffusion by the broncho-alveolar walls. The diffusion length of helium atoms during typical diffusion sensitizing times (a few milliseconds) exceeds the diameter of alveolar sacks (a few hundreds of micrometers). Hence, in the time scale of MR acquisition, 3He diffusion in alveolar space takes place in a restricted regime. The dependence of HP gases ADC values upon the dimensions of the alveolar space can be used as a non-invasive tool for probing the lung architecture at a sub-pixel level. Indeed, $3 \mathrm{He}$ ADC values have been shown to significantly increase in patients with emphysema compared with healthy volunteers [37]. These $3 \mathrm{He} \mathrm{ADC}$ changes in emphysematous lungs are attributed to morphological changes in alveolar structure and more specifically to airspace enlargements that characterize emphysema [37-40]. The longitudinal relaxation time, $\mathrm{T} 1$, of $3 \mathrm{He}$ in the lung is approximately $20 \mathrm{~s}$. The relaxation rate $\mathrm{R} 1$ of $3 \mathrm{He}$ is varying linearly with the partial pressure of oxygen due to dipolar interactions of $3 \mathrm{He}$ nucleus with paramagnetic molecular oxygen [41].

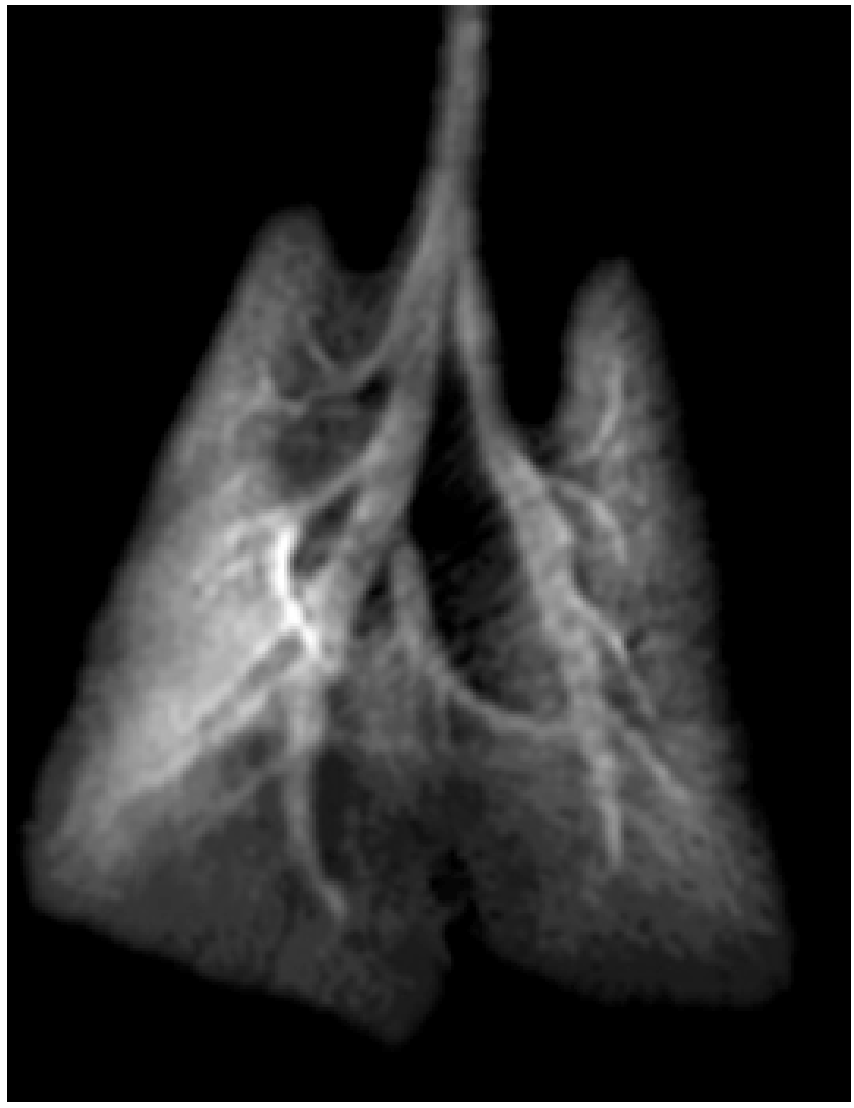

Fig. (3). Coronal 3D hyperpolarized 3He gas MR image in a normal rat.

By measuring the time variation of the relaxation time of HP $3 \mathrm{He}$ in the lungs, it is then possible to compute locally the alveolar oxygen concentration and the consumption rate of oxygen in vivo [42,43] (Fig. 4). The velocity of HP gas in the lungs can be measured from velocity-encoded MR imaging sequences and HP gases lung inflow or outflow can be derived from dynamic ventilation image series [44]. Among other applications, these dynamic gas MRI techniques have been used in animal models for the evaluation of bronchoconstrictive drug effects [45] and in clinical studies following lung transplant in patients [46]. Chemical shift imaging has been demonstrated using HP 129Xe. The high solubility and the large chemical shift (several hundreds of ppm) of xenon allow one to differentiate between xenon in alveoli and xenon dissolved in tissue. The so-called xenon polarization transfer contrast (XTC) technique aims to probe the xenon exchange between alveolar space and blood/tissue compartments [47]. The method is based on the selective destruction of xenon polarization in lung parenchyma. Owing to the rapid exchange of xenon between the gas and the tissue phase, the depolarization of xenon dissolved in tissue affects the xenon signal from the gaseous phase. Using an appropriate pixel-based signal analysis of this effect, the authors obtained so-called XTC lung images with a contrast related to the exchange rate of xenon between the tissue and the alveolar space. A similar approach, called CSSR (chemical shift saturation recovery) was recently demonstrated and applied in human studies to investigate the alveolar surface area per unit volume of gas [48]. Besides ventilation imaging, HP gas imaging has been applied for the assessment of tissue perfusion, the acquisition of 

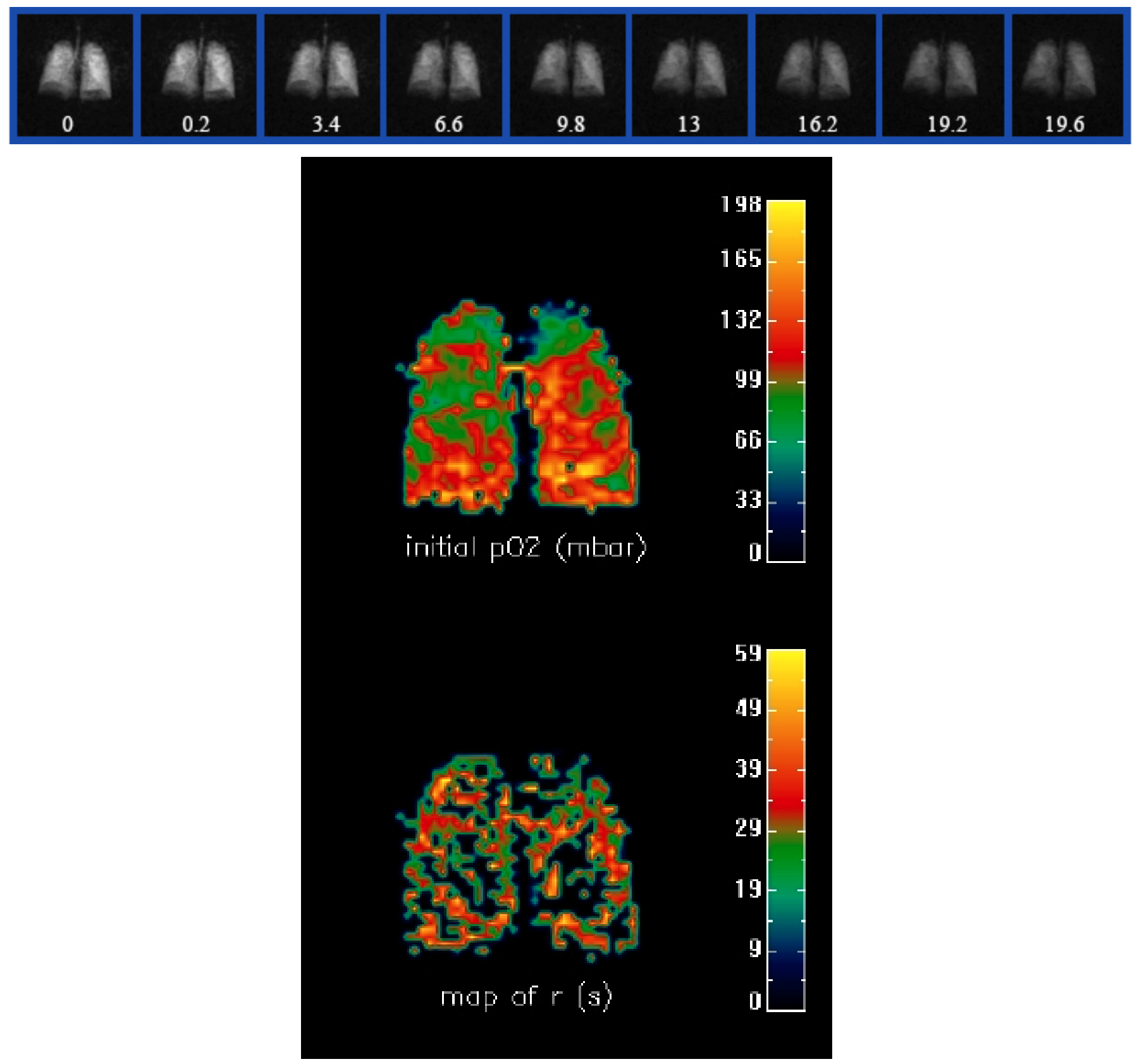

Fig. (4). The relaxation rate $\mathrm{R} 1$ of $3 \mathrm{He}$ is varying linearly with the partial pressure of oxygen due to dipolar interactions of $3 \mathrm{He}$ nucleus with paramagnetic molecular oxygen (top). Alveolar oxygen concentration and consumption rate of oxygen in a volunteer (bottom).

angiographic images and the characterization of biological tissues. These applications of HP gases have been restricted so far essentially to pre-clinical studies.

\section{Preclinical Examinations}

Emphysema disease in animal models has been extensively studied using $3 \mathrm{He}$ and $129 \mathrm{Xe}$ MRI. Elastaseinduced emphysema has been investigated in rat [38, 40], mouse [49] and rabbit [50] using $3 \mathrm{He}$ or $129 \mathrm{Xe}$ diffusion MRI. Measurements performed at end-expiratory inflation volume demonstrated an increase by $20 \%$ of ADC values in the lungs of elastase-treated animals compared with ADC values in healthy control animals [38]. When measurements were carried out at total lung capacity, $3 \mathrm{He}$ ADC values increased from $0.15 \mathrm{~cm} 2 / \mathrm{s}$ in normal rats to $0.18 \mathrm{~cm} 2 / \mathrm{s}$ in elastase-challenged animals; moreover, a significant correlation was found between the $3 \mathrm{He} \mathrm{ADC}$ values and the alveolar internal area assessed by histology in lungs fixed with formalin at an airway pressure corresponding to the total lung capacity [40]. Similarly, $3 \mathrm{He}$ ADC values averaged over the entire lungs were found to be approximately $25 \%$ higher in emphysema mice than in healthy animals [35].

As mentioned previously, it is possible to compute the alveolar partial pressure of oxygen, $\left(\mathrm{pO}_{2}\right)$ in vivo from the relaxation time of the $\mathrm{HP} 3 \mathrm{He}$ in the lungs. As the intrapulmonary oxygen partial pressure distribution is governed by local ventilation, perfusion and $\mathrm{O}_{2}$ uptake, $\mathrm{pO}_{2}$ assessment can be used to evaluate lung function. As a matter of fact, the determination of $\mathrm{pO}_{2}$ values and of their 
time evolution during breathhold represents an indirect measure of the ventilation/perfusion ratio. The potential of $3 \mathrm{He}$ imaging for detecting perfusion abnormalities based on $\mathrm{pO}_{2}$ measurement was demonstrated in an experimental pig model [51]. After isolated pulmonary arterial occlusion using a balloon catheter, a focal T1 reduction corresponding to an abnormally high $\mathrm{pO}_{2}$ (related to the absence of perfusion) was observed, which normalized upon deflation of the balloon. More recently, $\mathrm{pO}_{2}$ imaging and oxygen depletion rate imaging was extended to small animal studies in rats and mice [52,53]. The potential of $3 \mathrm{He}$ MRI for assessing airways constriction has been demonstrated in methacholineinduced bronchoconstriction in rat models [45]. Using a Cine-MRI approach in which image acquisition was synchronized with the inhalation of the gas mixture $33 \mathrm{He}$ with oxygen and nitrogen), heterogeneously distributed airways constriction was observed, resulting in a partition of the lung between ventilated and non-ventilated regions. The diameter of the main airways decreased by approximately $11 \%$ following methacholine injection. In a methacholineinduced broncho-constriction rat model [45], dynamic ventilation image series obtained from a single breath were used to generate parametric pixel-by-pixel maps of gas arrival time, filling time constant, inflation rate and gas volume and to assess these parameters in distal areas of the lung. Quantitative and regional analysis of gas flow, volume and arrival time demonstrated statistically significant differences between the baseline and constricted states. These differences were attributed to constriction of peripheral airways.

\section{Clinical Applications}

Longitudinal studies or follow-up examinations for treatment or therapy monitoring are limited by the ionizing nature of the standard clinical imaging techniques (radiography, CT or scintigraphy). HP gases imaging represents a relevant diagnostic modality when multiple examinations are required for improving the patient management care. Up to now, the clinical applications of HP gases have been focused mainly on the investigation of three lung diseases: emphysema, cystic fibrosis and asthma.

In clinical studies, the regional measurement of $3 \mathrm{He}$ ADC values has been used to evaluate the severity of emphysema in patients [54-56]. This approach is supported by the good correlation observed between the $3 \mathrm{He}$ ADC values and alveolar dimensions [40]. Additionally, the $3 \mathrm{He}$ ADC values have been shown to correlate with spirometric indexes such as FEV1 (forced expiratory volume in 1 second) in healthy volunteers and in emphysema patients [57]. $3 \mathrm{He}$ imaging has been also applied for the investigation of young patients (children and adolescent) with cystic fibrosis. Since the radiation exposure experienced in case of ionizing imaging modalities is problematic for children, $3 \mathrm{He}$ MRI represents an interesting alternative to standard imaging technique. $3 \mathrm{He}$ MRI has been demonstrated to be well suited for the visualization of ventilation defects (Fig. 5) and for evaluation of the efficacy of therapies such as physical therapies or bronchodilator inhalation [58-60]. Asthma disease is characterized by the inflammation and the obstruction of small airways. Several studies have investigated and demonstrated the potential of $\mathrm{HP} 3 \mathrm{He}$ in clinical studies with asthmatic patients [61-63]. It has been shown that small and reversible ventilation defects that characterize asthma can be detected using HP $3 \mathrm{He}$ and that the efficiency of bronchodilator and physical challenge can be locally assessed. Furthermore, the variations in airflow obstructions as depicted with $3 \mathrm{He}$ MRI correlate with the clinical evaluation of asthma severity and spirometry measurements.

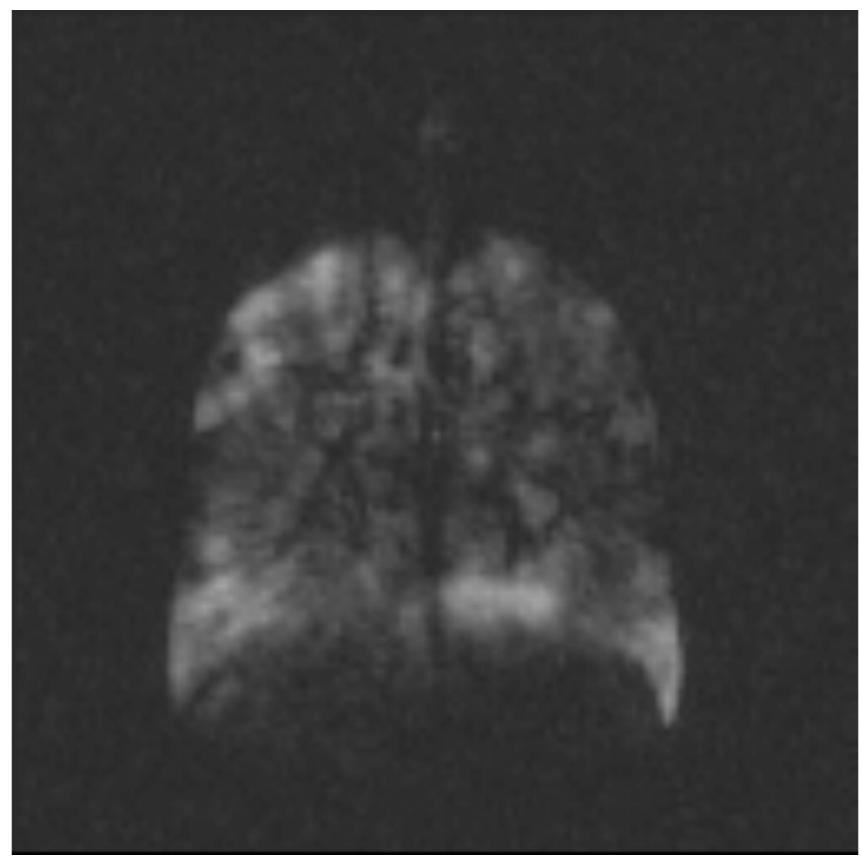

Fig. (5). Coronal hyperpolarized $3 \mathrm{He}$ gas $\mathrm{MR}$ image in a patient with cystic fibrosis with multiple ventilation defects.

\section{CONCLUSION}

CT plays a major role in the imaging approach to structure and function in ARDS. CT has an impact on the optimization of the ventilatory strategies. However, great improvement has been made in MRI of the pulmonary parenchyma during the past years. The lung will not remain the forgotten organ for MR imaging in the future. Promising research activities are under way to introduce functional MRI of the lung. MRI will offer visualization of lung morphology as well as functional assessment of ventilation and pulmonary perfusion in a single examination.

\section{REFERENCES}

[1] Bergin C, Glover G, Pauly J. Lung parenchyma: magnetic susceptibility in MR imaging. Radiology 1991; 180: 845-8.

[2] Müller N, Mayo J, Zwirewich C. Value of MR imaging in the evaluation of chronic infiltrative lung disease: comparison with CT. Am J Roentgenol 1992; 158: 1205-9.

[3] King M, Bergin C, Ghadishah E, Yi E, Clark J. Detecting pulmonary abnormalities on magnetic resonance images in patients with usual interstitial pneumonitis: effects of varying window settings and gadopentetate dimeglumine. Acad Radiol 1996; 3: 300-7.

[4] Matsumoto S, Mori H, Miyake H, et al. MRI signal characteristics of progressive massive fibrosis in silicosis. Clin Radiol 1998; 53: 510-4.

[5] Kalaitzoglou I, Drevelengas A, Palladas P, Asimaki A. MRI appearance of pulmonary Wegener's granulomatosis with concomitant splenic infarction. Eur Radiol 1998; 8: 367-70.

[6] Berthezène Y, Vexler V, Kuwatsuru R, et al. Differentiation of alveolitis and pulmonary fibrosis with a macromolecular MR imaging contrast agent. Radiology 1992; 185: 97-103. 
[7] Carroll F, Lloyd J, Nolop K, Collins J. MR imaging parameters in the study of lung water. Invest Radiol 1985; 20: 381-7.

[8] Schmidt H, Tsay D-G, Higgins C. Pulmonary edema: a MR study of permeability and hydrostatic types in animals. Radiology 1986; 158: 297-302.

[9] Skalina S, Kundel H, Wolf G, Marshall B. The effect of pulmonary edema on proton nuclear magnetic resonance relaxation times. Invest Radiol 1984; 19: 7-9.

[10] Mayo J, MacKay A, Whittall K, Baile E, Parǿ P. Measurement of lung water content and pleural pressure gradient with magnetic resonance imaging. J Thorac Imaging 1995; 10: 73-81.

[11] Caruthers S, Paschal C, Pou N, Harris T. Relative quantification of pulmonary edema with noncontrast-enhanced MRI. J Magn Reson Imaging 1997; 7: 544-50.

[12] Caruthers S, Paschal C, Pou N, Roselli R, Harris T. Regional measurements of pulmonary edema by using magnetic resonance imaging. J Appl Physiol 1998; 84: 2143-53.

[13] Berthezène Y, Vexler V, Jerome H, Sievers R, Moseley M, Brasch R. Differentiation of capillary leak and hydrostatic pulmonary edema with a macromolecular MR imaging contrast agent. Radiology 1991; 181: 773-7.

[14] Edelman R, Siewert B, Adamis M, Gaa J, Laub G, Wielopolski P. Signal targeting with alternating radiofrequency (STAR) sequences: application to MR angiography. J Magn Reson Med 1994; 31:233-8.

[15] Ohno Y, Murase K, Higashino T, et al. Assessment of bolus injection protocol with appropriate concentration for quantitative assessment of pulmonary perfusion by dynamic contrast-enhanced MR imaging, J Magn Reson Imaging 2007; 25: 55-65.

[16] Eichinger M, Puderbach M, Fink C, et al. Contrast-enhanced 3D MRI of lung perfusion in children with cystic fibrosis-initial results. Eur Radiol 2006; 16: 2147-52.

[17] David V, Chen Q, Goldfarb J, Levin D, Edelman R. Comprehensive diagnosis of pulmonary embolism using MR imaging. Radiology 1997; 201: 411-2.

[18] Adam G, Neuerburg J, Spüntrup E, Mühler A, Scherer K, Günther R. Gd-DTPA-cascade-polymer: potential blood pool contrast agent for MR imaging. J Magn Reson Imaging 1994; 4: 462-6.

[19] Marchal G, Bosmans H, Hecke P, Jiang Y, Aerts P, Bauer H. Experimental Gd-DTPA polylysine enhanced MR angiography: sequence optimization. J Comput Assist Tomogr 1991; 15: 711-5.

[20] Berthezène Y, Vexler V, Price D, Wisner-Dupon J, Moseley M, Aicher K, Brasch R. Magnetic resonance imaging detection of an experimental pulmonary perfusion deficit using a macromolecular contrast agent. Polylysine-gadolinium-DTPA40. Invest Radiol 1992; 27: 346-51.

[21] Stock K, Chen Q, Levin D, Hatabu H, Edelman R. Demonstration of gravity-dependent lung perfusion with contrast-enhanced magnetic resonance imaging. J Magn Reson Imaging 1999; 9: $557-$ 61.

[22] Berthezène Y, Croisille P, Bertocchi M, Houzard C, Bendib K, Revel D. Lung perfusion demonstrated by contrast-enhanced dynamic magnetic resonance imaging: application to unilateral lung transplantation. Invest Radiol 1997; 32: 351-6.

[23] Edelman RR, Hatabu H, Tadamura E, Li W, Prasad PV. Noninvasive assessment of regional ventilation in the human lung using oxygen-enhanced magnetic resonance imaging. Nat Med 1996; 2: 1236-9.

[24] Chen Q, Jakob PM, Griswold MA, Levin DL, Hatabu H, Edelman RR. Oxygen enhanced MR ventilation imaging of the lung. MAGMA 1998; 7: 153-61.

[25] Stock KW, Chen Q, Morrin M, Hatabu H, Edelman RR. Oxygenenhanced magnetic resonance ventilation imaging of the human lung at 0.2 and 1.5 T. J Magn Reson Imag 1999; 9: 838-41

[26] Mai VM, Liu B, Li W, Polzin J, Kurucay S, Chen Q, Edelman RR. Influence of oxygen flow rate on signal and $\mathrm{T}(1)$ changes in oxygen-enhanced ventilation imaging. J Magn Reson Imag 2002; 16: 37-41.

[27] Ohno Y, Hatabu H, Takenaka D, Van Cauteren M, Fujii M, Sugimura K. Dynamic oxygen enhanced MRI reflects diffusing capacity of the lung. J Magn Reson Med 2002; 47: 1139-44.

[28] Molinari F, Gaudino S, Fink C, et al. Simultaneous cardiac and respiratory synchronization in oxygen-enhanced magnetic resonance imaging of the lung using a pneumotachograph for respiratory monitoring. Invest Radiol 2006; 41: 476-85.
[29] Müller CJ, Schwaiblmair M, Scheidler J, et al. Pulmonary diffusing capacity: assessment with oxygen-enhanced lung MR imaging preliminary findings. Radiology 2002; 222: 499-506.

[30] Ohno Y, Hatabu H, Higashino T, et al. Oxygen-enhanced MR imaging: correlation with postsurgical lung function in patients with lung cancer. Radiology 2005; 236: 704-11.

[31] Albert MS, Cates GD, Driehuys B, et al. Biological magnetic resonance imaging using laser-polarized 129Xe. Nature 1994; 370: 199-201.

[32] Middleton H, Black RD, Saam B, et al. MR imaging with hyperpolarized 3He gas. J Magn Reson Med 1995; 33: 271-5.

[33] Ebert M, Grossmann T, Heil W, et al. Nuclear magnetic resonance in humans using hyperpolarized helium3. Lancet 1996; 347: 12979.

[34] MacFall JR, Charles HC, Black RD, et al. Human lung air spaces: potential for MR imaging with hyperpolarized He-3. Radiology 1996; 200: 553-8.

[35] Viallon M, Cofer GP, Suddarth SA, et al. Functional MR microscopy of the lung with hyperpolarized 3He. J Magn Reson Med 1999; 41: 787-92.

[36] Chen BT, Yordanov AT, Johnson GA. Ventilation-synchronous magnetic resonance microscopy of pulmonary structure and ventilation in mice. J Magn Reson Med 2005; 53: 69-75.

[37] Saam BT, Yablonskiy DA, Kodibagkar VD, et al. MR imaging of diffusion of (3)He gas in healthy and diseased lungs. J Magn Reson Med 2000; 44: 174-9.

[38] Chen XJ, Hedlund LW, Möller HE, Chawla MS, Maronpot RR, Johnson GA. Detection of emphysema in rat lungs by using magnetic resonance measurements of $3 \mathrm{He}$ diffusion. Proc Natl Acad Sci USA 2000; 10: 11478-81.

[39] Yablonskiy DA, Sukstanskii AL, Leawoods JC, et al. Quantitative in vivo assessment of lung microstructure at the alveolar level with hyperpolarized 3He diffusion MRI. Proc Natl Acad Sci 2002; 99: 3111-6.

[40] Peces-Barba G, Ruiz-Cabello J, Cremillieux Y, et al. Helium-3 MRI diffusion coefficient: correlation to morphometry in a model of mild emphysema. Eur Respir J 2003; 22: 14-9.

[41] Saam B, HapperW, Middleton H. Nuclear relaxation of $3 \mathrm{He}$ in the presence of $\mathrm{O}_{2}$. Phys Rev A 1995; 52: 862-5.

[42] Eberle B, Weiler N, Markstaller $\mathrm{K}$, et al. Analysis of intrapulmonary $\mathrm{O}(2)$ concentration by MR imaging of inhaled hyperpolarized helium-3. J Appl Physiol 1999; 87: 2043-52.

[43] Wild JM, Fichele S, Woodhouse N, Paley MN, Kasuboski L, van Beek EJ. 3D volume-localized $\mathrm{pO}_{2}$ measurement in the human lung with 3He MRI. J Magn Reson Med 2005; 53: 1055-64.

[44] Dupuich D, Berthezène Y, Clouet PL, Stupar V, Canet E, Cremillieux Y. Dynamic $3 \mathrm{He}$ imaging for quantification of regional lung ventilation parameters. J Magn Reson Med 2003; 50: 777-83.

[45] Mosbah K, Cre'millieux Y, Adeleine $\mathrm{P}$, et al. Quantitative measurements of regional lung ventilation using helium-3 MRI in a methacholine-induced bronchoconstriction model. J Magn Reson Imag 2006; 24: 611-16.

[46] Gast KK, Puderbach MU, Rodriguez I, et al. Distribution of ventilation in lung transplant recipients: evaluation by dynamic $3 \mathrm{He}-\mathrm{MRI}$ with lung motion correction. Invest Radiol 2003; 38: 341-8.

[47] Ruppert K, Brookeman JR, Hagspiel KD, Mugler JP 3rd. Probing lung physiology with xenon polarization transfer contrast (XTC). J Magn Reson Med 2000; 44: 349-57.

[48] Patz S, Muradian I, Hrovat MI, et al. Human pulmonary imaging and spectroscopy with hyperpolarized (129)Xe at $0.2 \mathrm{~T}$. Acad Radiol 2008; 15: 713-27.

[49] Dugas JP, Garbow JR, Kobayashi DK, Conradi MS Hyperpolarized (3)He MRI of mouse lung. J Magn Reson Med 2004; 52: 1310-7.

[50] Mata JF, Altes TA, Cai J, et al. Evaluation of emphysema severity and progression in a rabbit model: a comparison of hyperpolarized He-3 and 129Xe diffusion MRI with lung morphometry. J Appl Physiol 2006; 102: 1273-80.

[51] Jalali A, Ishii M, Edvinsson JM, et al. Detection of simulated pulmonary embolism in a porcine model using hyperpolarized $3 \mathrm{He}$ MRI. J Magn Reson Med 2004; 51: 291-8.

[52] Cieslar K, Stupar V, Canet-Soulas E, Gaillard S, Cremillieux Y. Alveolar oxygen partial pressure and oxygen depletion rate 
mapping in rats using (3)He ventilation imaging. J Magn Reson Med 2007; 57: 423-30.

[53] Cieslar K, Alsaid H, Stupar V, et al. Measurement of nonlinear pO2 decay in mice lungs using 3He-MRI. NMR Biomed 2007; 20: 383-91.

[54] Ley S, Zaporozhan J, Morbach A, et al. Functional evaluation of emphysema using diffusion-weighted 3Helium-magnetic resonance imaging, high-resolution computed tomography, and lung function tests. Invest Radiol 2004; 39: 427-34.

[55] Swift AJ, Wild JM, Fichele S, et al. Emphysematous changes and normal variation in smokers and COPD patients using diffusion 3He MRI. Eur J Radiol 2005; 54: 352-8.

[56] Fain SB, Panth SR, Evans MD, et al. Early emphysematous changes in asymptomatic smokers: detection with $3 \mathrm{He} \mathrm{MR}$ imaging. Radiology 2006; 239: 875-83.

[57] Salerno M, de Lange EE, Altes TA, et al. Emphysema: hyperpolarized helium 3 diffusion MR imaging of the lungs compared with spirometric indexes - initial experience. Radiology 2002; 222: 252-60.

[58] Donnelly LF, MacFall JR, McAdams HP, et al. Cystic fibrosis: combined hyperpolarized $3 \mathrm{He}$-enhanced and conventional proton
MR imaging in the lung - preliminary observations. Radiology 1999; 212: 885-9.

[59] Altes TA, de Lange EE. Applications of hyperpolarized helium-3 gas magnetic resonance imaging in pediatric lung disease. J Magn Reson Imag 2003; 14: 231-6.

[60] Mentore K, Froh DK, de Lange EE, Brookeman JR, Paget-Brown $\mathrm{AO}$, Altes TA. Hyperpolarized HHe 3 MRI of the lung in cystic fibrosis: assessment at baseline and after bronchodilator and airway clearance treatment. Acad Radiol 2005; 12: 1423-9.

[61] Altes TA, Powers PL, Knight-Scott J, et al. Hyperpolarized $3 \mathrm{He}$ MR lung ventilation imaging in asthmatics: preliminary findings. J Magn Reson Imag 2001; 13: 378-84.

[62] Samee S, Altes T, Powers P, et al. Imaging the lungs in asthmatic patients by using hyperpolarized helium-3 magnetic resonance: assessment of response to methacholine and exercise challenge. $\mathrm{J}$ Allergy Clin Immunol 2003; $111: 1205-11$.

[63] de Lange EE, Altes TA, Patrie JT, et al. Evaluation of asthma with hyperpolarized helium-3 MRI: correlation with clinical severity and spirometry. Chest 2006; 130: 1055-62.

\section{(C) Y. Berthezène; Licensee Bentham Open.}

This is an open access article licensed under the terms of the Creative Commons Attribution Non-Commercial License (http: //creativecommons.org/licenses/by-nc/ 3.0/) which permits unrestricted, non-commercial use, distribution and reproduction in any medium, provided the work is properly cited. 